\title{
OUTER SURFACE CHANGES OF PSEUDOMONAS AERUGINOSA IN RELATION TO RESISTANCE TO GENTAMICIN AND CARBENICILLIN
}

\author{
T. Katsorchis*, N. J. Legakis, B. Shearer, V. Genmmata and H. Pataryas* \\ Department of Microbiology, Medical School, University of Athens Goudi, Athens, and \\ *Department of Biology, University of Athens, Panepistimioupolis, Kouponia, \\ Athens 157.71, Greece
}

\begin{abstract}
Summary. The outer surface structure of clinical isolates of Pseudomonas aeruginosa resistant to carbenicillin or gentamicin or both was studied by thin-section electronmicroscopy and compared with that of sensitive isolates. The latter had a fairly smooth outer layer. Strains resistant to both antibiotics were characterised by extrusions that appeared to constitute extensions of the outer membrane. The outer membrane appeared wavy with distortion of its tripartite structure. The latter findings were also present in isolates resistant to only one of the two antibiotics. The disorganisation of the outer membrane might contribute to the expression of resistance.
\end{abstract}

\section{INTRODUCTION}

The importance of the cell envelope and particularly the outer membrane (OM) of Pseudomonas aeruginosa in the expression of resistance to antimicrobial drugs by an exclusion mechanism has been well documented (Nakae and Nikaido, 1975; Osborn and $\mathrm{Wu}, 1980)$.

In strains of $P$. aeruginosa that are resistant to carbenicillin (Barrett and Asscher, 1972) or to polymyxin (Gilleland and Lyle, 1979) because of a permeability defect, a correlation between the chemistry of the OM and resistance has been indicated. Alterations of $O M$ protein have also been reported for $P$. aeruginosa mutants resistant to polymyxin, EDTA and gentamicin (Nicas and Hancock, 1980).

It has also been shown that variants of $P$. aeruginosa habituated to increased concentrations of carbenicillin or gentamicin are characterised by increased adherence, evidently due to an altered surface as detected by electronmicroscopy (Lianou et al., 1980). The morphological responses of $P$. aeruginosa to $\mathrm{N}$-formimidoyl thienamycin, azthreonam, ceftazidime and cefoperazone were studied by transmission electronmicroscopy (Elliot and Greenwood, 1984).

In this investigation we have studied the fine structure of $P$. aeruginosa clinical isolates that were resistant to carbenicillin or gentamicin or both. 


\section{MATERIAL AND METHODS}

Organisms. Ten fresh isolates of $P$. aeruginosa derived from various clinical sources were used. They were identified by previously published criteria (Legakis and Papavassiliou, 1975) and were chosen to differ only in their susceptibility to gentamicin and carbenicillin (table). Resistant isolates had an inhibition zone of not greater than $8 \mathrm{~mm}$ with gentamicin disks and 10 $\mathrm{mm}$ with carbenicillin disks. All strains were grown, with aeration and stirring, at $37^{\circ} \mathrm{C}$ in Mueller Hinton Broth (Difco) with inocula taken from an 18-h broth culture.

Susceptibility testing. The single-disk diffusion method was used as described by Bauer $e t$ al. (1966). Zones of inhibition were measured with a ruler to the nearest millimeter. All disks were obtained from Bio-Merieux, Paris, France.

Electronmicroscopy. Cultures in the exponential phase were harvested by centrifugation at $3000 \mathrm{~g}$ for $20 \mathrm{~min}$. The pellets were prefixed in $0 \cdot 1 \mathrm{M}$ sodium cacodylate containing glutaraldehyde $3 \% \mathrm{w} / \mathrm{v}$ and formaldehyde $2 \% \mathrm{v} / \mathrm{v}$. Postfixation was for $30 \mathrm{~min}$ at $4 \mathrm{C}^{\circ}$ in $2 \% \mathrm{w} / \mathrm{v}$ $\mathrm{OsO}_{4}$. Thin sections were cut on a MT-2 ultramicrotome with glass knives. They were collected on copper grids, double stained with uranyl acetate and lead citrate and then examined with a Phillips EM 200 electron microscope operating at $80 \mathrm{kV}$.

Serotyping. Unabsorbed antisera, sixteen (1-16) monovalent and four pools from Institut Pasteur, Paris, were used for serotyping the strains. Cultures grown on Mueller-Hinton Agar (MHA) (Difco) at $37^{\circ} \mathrm{C}$ for $18-24 \mathrm{~h}$ were used as antigens. Typing was done by the slide-agglutination technique (Brokopp et al., 1977; Legakis et al., 1982).

Carbenicillinase activity. Hydrolysis of carbenicillin was detected in intact cells, disrupted cells and supernates in MHA containing carbenicillin at a twofold concentration of that required to inhibit the sensitive strain (NCTC10490) incorporated into the medium at a density of about $10^{4} \mathrm{cfu} / \mathrm{ml}$. Strain PA401, producing the PSE-4 enzyme, kindly provided by Dr G. Rolinson (Beecham Research Laboratories, Surrey) was used as a positive control.

Assay for aminoglycoside-modifying enzymes. Extracts of the strains were examined for the presence of aminoglycoside-adenylylating, -acetylating and -phosphorylating enzymes as described by Holmes et al. (1974).

\section{RESULTS}

Thin sections of sensitive strains (fig. 1) showed the typical trilaminar unitmembrane appearance of gram-negative bacteria with a fairly smooth surface. Strains resistant to carbenicillin and gentamicin (fig. 2) were characterised by the presence of well defined globular bulges, appearing to be extensions of the OM, which showed undulations and distortion of its tripartite structure. The undulations and altered stratification characterised also the strains resistant only to gentamicin (fig. 3). The membrane of the carbenicillin-resistant strains showed the same features.

Although the number of isolates was limited, it seems that resistant strains were differentiated from their sensitive counterparts in terms of the $\mathrm{O}$-antigen reaction with specific antisera. As shown in the table, serotype O6 included the three sensitive strains, while resistant strains were expressed mainly by serotype $O$ "PME", agglutinating in pooled antisera but not in the respective individual antisera. It is noteworthy that no resistant strain belonged to serotype O6, confirming previous results (Legakis et al., 1982).

Most of the carbenicillin-resistant strains did not produce $\beta$-lactamase and most strains resistant to aminoglycosides, excepting amikacin, did produce aminoglycosidemodifying enzymes (table). 


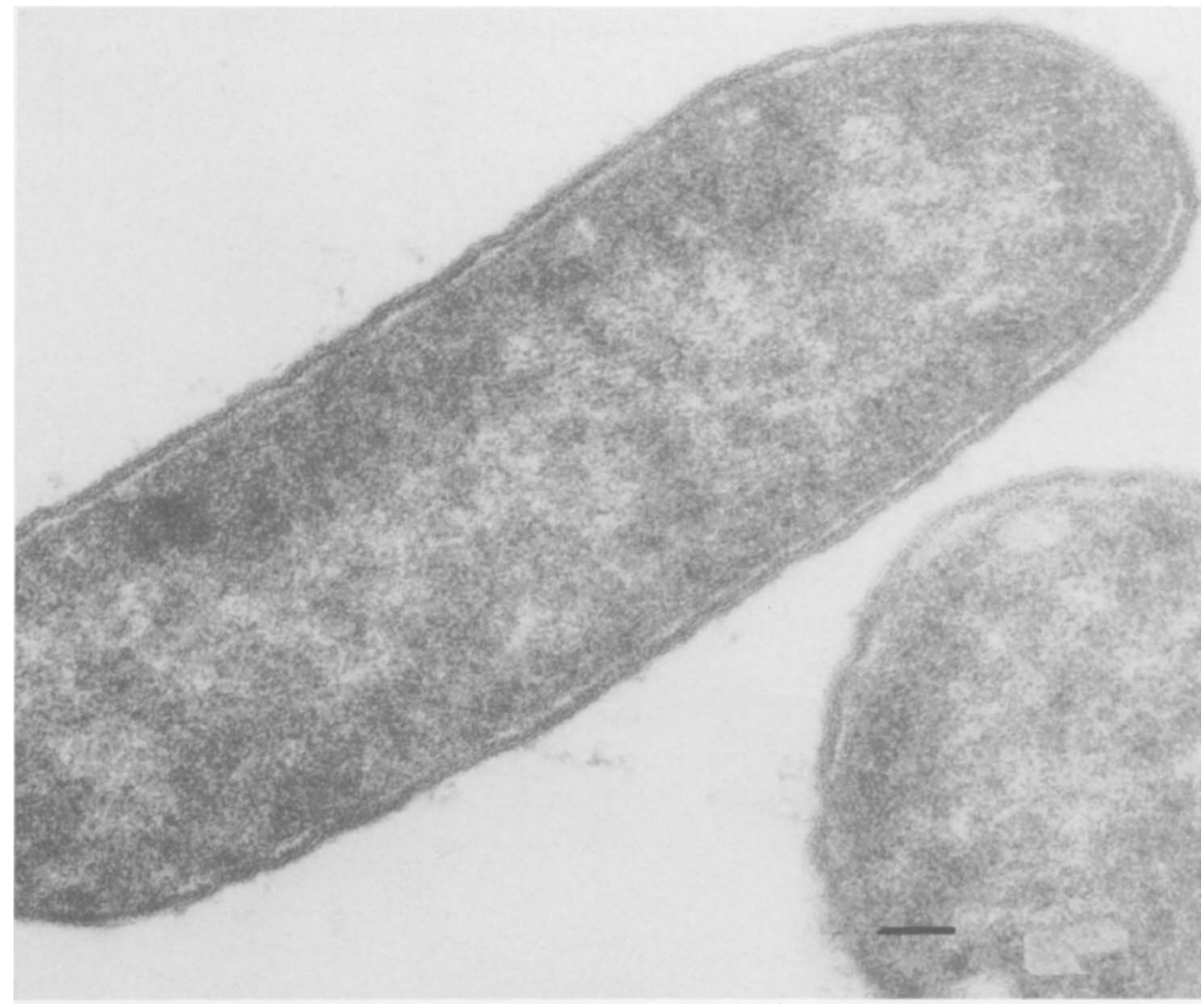

FIG. 1-Thin section of $P$. aeruginosa strain PA428 sensitive to carbenicillin and gentamicin. Bar $=0 \cdot 2 \mu \mathrm{m}$.

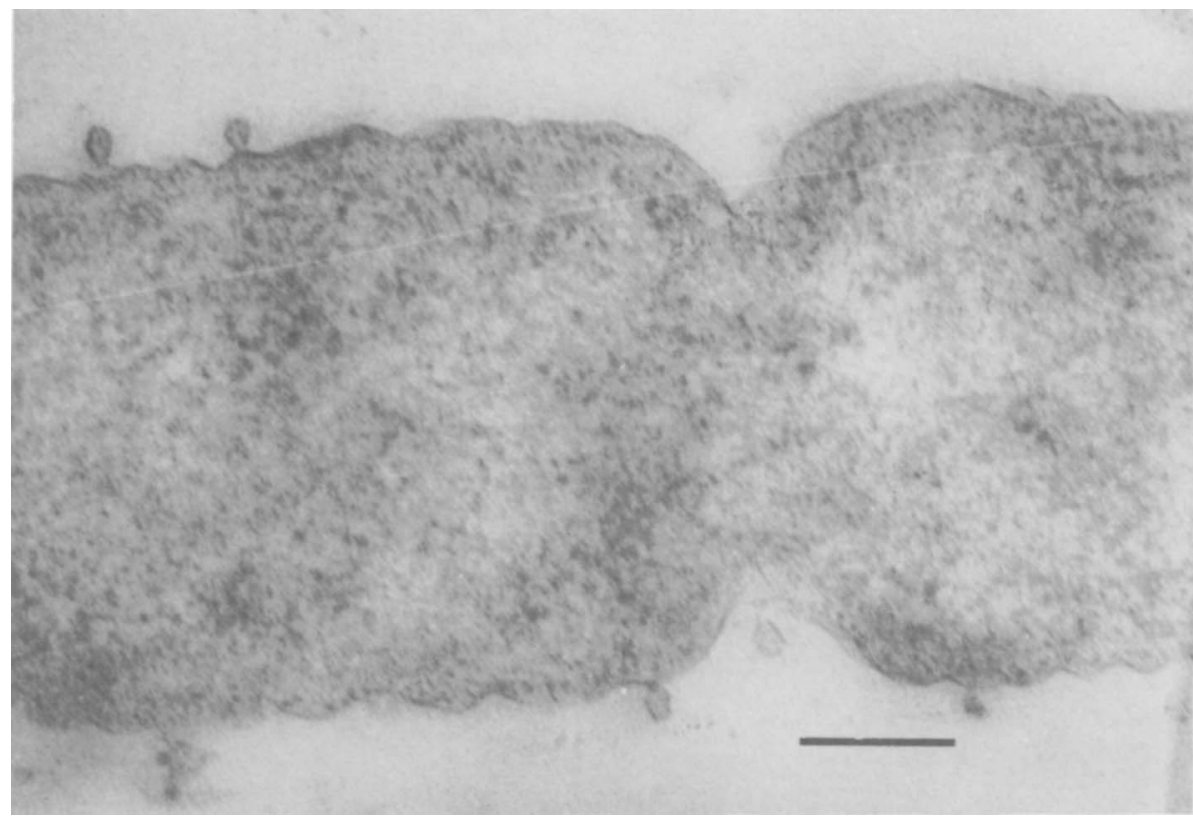

FIG. 2-Thin section of a clinical isolate of $P$. aeruginosa (strain PA388) resistant to carbenicillin and gentamicin. Bar $=0.2 \mu \mathrm{m}$. 


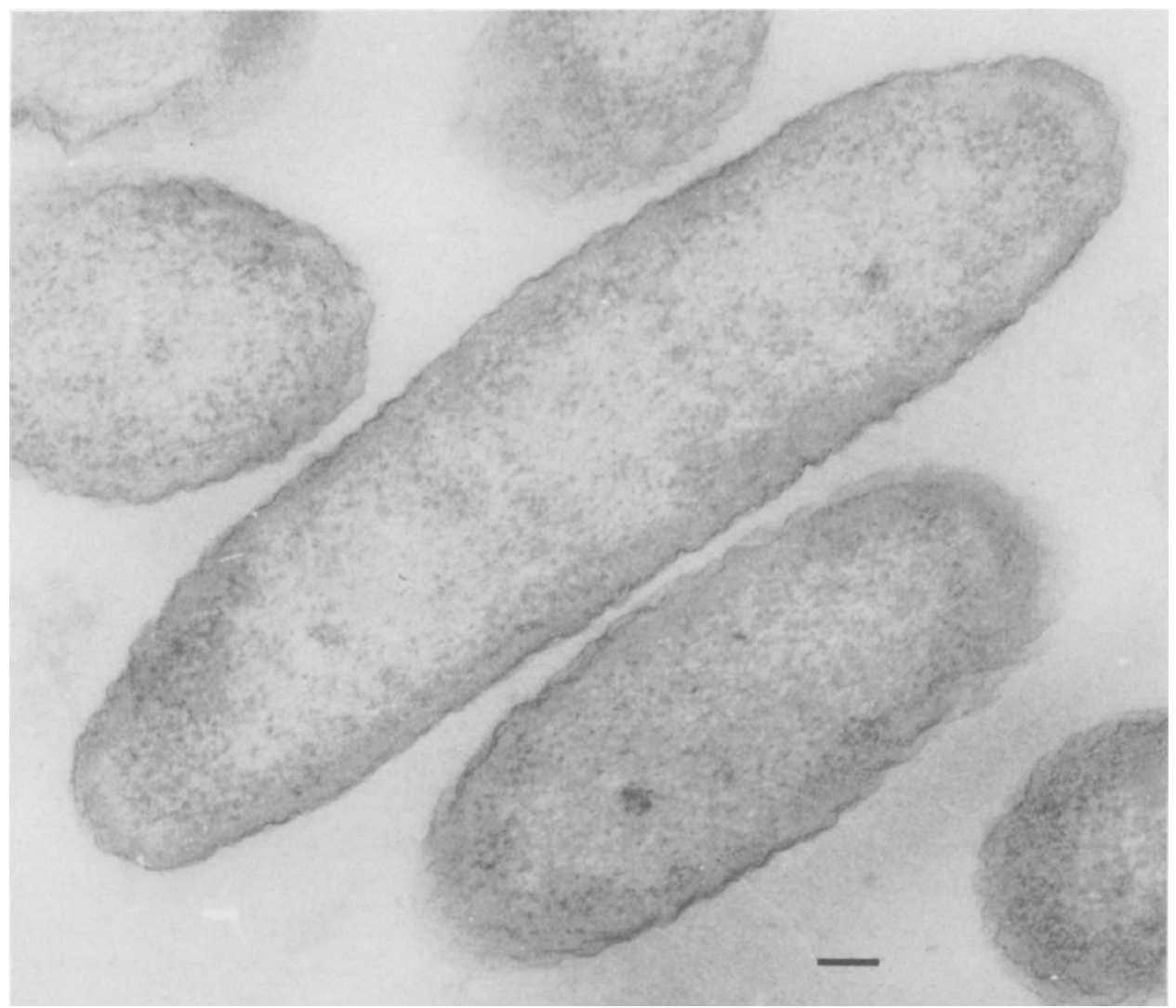

FIG. 3-Thin section of a clinical isolate of $P$. aeruginosa (strain PA391) resistant to gentamicin but sensitive to carbenicillin. $\mathrm{Bar}=0 \cdot 2 \mu \mathrm{m}$.

\section{TABLE}

Resistance phenotype, $O$ serotype, carbenicillinase and aminoglycoside-modifying enzyme production in $P$. aeruginosa

\begin{tabular}{llccl}
\hline Strain no. & Resistance phenotype & O serotype & $\begin{array}{c}\text { Hydrolysis of } \\
\text { carbenicillin }\end{array}$ & $\begin{array}{c}\text { Aminoglycoside-modifying } \\
\text { enzyme }\end{array}$ \\
\hline Pa28-0 & $\mathrm{Na}, \mathrm{C}, \mathrm{Te}$ & 6 & $\mathrm{NT}$ & ND \\
$\mathrm{Pa388}$ & $\mathrm{Na}, \mathrm{C}, \mathrm{Te}, \mathrm{Cb}, \mathrm{Gm}, \mathrm{Tm}, \mathrm{Si}$ & $\mathrm{PME}$ & - & ANT-2" \\
Pa389 & Na, C, Te, Cb, Gm, Tm, Si & PME & - & AAC(6)-II \\
Pa390 & Na, C, Te, Cb, Gm, Tm, Si & PME & - & ANT-2"' \\
Pa391 & Na, C, Te, Gm, Tm, Si & 4 & 5 & ANT-2" \\
Pa400 & Na, C, Te, Cb & 5 & + & NT \\
Pa402 & Na, C, Te, Cb & NT & + & NT \\
Pa403 & Na, C, Te & 6 & NT & NT \\
Pa405 & Na, C, Te, Gm, Tm, Si & PME & NT & ANT-2" \\
Pa428 & Na, C, Te & 6 & NT & NT \\
\hline
\end{tabular}

$\mathrm{Na}=$ nalidixic acid; $\mathrm{C}=$ chloramphenicol; $\mathrm{Tc}=$ tetracycline; $\mathrm{Cb}=$ carbenicillin; $\mathrm{Gm}=$ gentamicin; $\mathrm{Tm}=$ tobramycin; $\mathrm{Si}=$ sissomycin. All strains were sensitive to polymyxin and amikacin.

$\mathrm{PME}=$ agglutinating in pooled antisera $(2,5,15,16)$ but not in the individual antisera.

NT $=$ not tested. ANT-2" aminoglycoside $2^{\prime \prime}-0$ nucleotidyl-transferase; ANT(6)-II aminoglycoside $6^{\prime}$-N-acetyltranferase-II. 


\section{DisCUSSION}

Evidence has been produced that lipopolysaccharides (LPS) linked with proteins in a protein-LPS complex (Barrett and Asscher, 1972; Stinnett et al., 1973) occupies, as in the Enterobacteriaceae (Nikaido and Nakae, 1979) the outer half of the OM in $P$. aeruginosa (Eagon, 1974; Gilleland and Murray, 1976). The supramolecular organisation of these molecules results in the formation of transmembrane pores for the entrance of hydrophilic substances, including polar antibiotics, into the cells (Nakae and Nikaido, 1975).

This architecture appears to be disturbed in LPS-defective mutants of $P$. aeruginos $a$ lacking polymerised O-antigenic side chains, in the sense of redistribution of membrane components so that more hydrophobic molecules (phospholipids) are exposed to the surface of the membrane (Nakae and Nikaido, 1975; Meadow et al., 1978). These changes were similar to those observed in our resistant isolates and to those found after treatment with polymyxin (Koike et al., 1969). The bulges observed in isolates resistant to carbenicillin or gentamicin or both, as in LPS-deficient mutants (Meadow et al., 1978), may have been fragments of the outer membrane, as are found in Escherichia coli (Hoekstra et al., 1976), which are extruded from the bacterial surface and which, because of their lipophilicity, are attached to the hydrophobic surface of the OM. LPS appears to be responsible for the heat-stable O-antigenic specificity (Chester et al., 1973).

If it is assumed that LPS alterations are present in the resistant isolates, the data of the present paper might provide an explanation for the differential distribution of $\mathrm{O}$ serotypes among sensitive and resistant isolates as reported by Legakis et al. (1982) and Penketh et al. (1983). This hypothesis is supported by previous reports on the loss of the specific $\mathrm{O}$-serotyping reaction in $P$. aeruginosa mutants characterised by defective structure of the O-antigenic region of LPS (Meadow, 1975).

The fact that the sensitivity of the LPS-defective mutants was greater (Meadow, 1975; Koval and Meadow, 1977) or equal to (Meadow et al., 1978) that of their parent strains, is not apparently relevant to the above consideration. However alterations of the OM-proteins responsible for an increase of the sensitivity could most probably also exist as occurs in the heptose-deficient mutants of $E$. coli (Koplow and Goldfine, 1974) and Salmonella typhimurium (Ames et al., 1974; Roantree et al., 1977) and in the supersensitive strains of $P$. aeruginosa isolated from patients with cystic fibrosis (Irvin et al., 1981).

At present it is difficult to assign any role to OM-surface alterations for the expression of resistance. However it has been suggested that impaired cellular permeability might reflect differences in the detailed organisation of the OM (Meadow, 1975). The present results provide indirect evidence for the involvement of impaired permeability as the expression of resistance in the clinical isolates confirming previous reports (Bryan and Van Den Elzen, 1977; Richmond, 1978; Davies 1979; Legakis et al., 1979).

The presence of carbenicillinase and aminoglycoside-modifying enzymes in some of our isolates does not necessarily exclude the importance of impaired permeability as the expression of resistance. Studies with $\beta$-lactam antibiotics (Richmond and Curtis, 1974) have demonstrated that $\beta$ lactamases, even though strategically located in the periplasmic space, provide poor protection against $\beta$-lactam attack when the antibiotic 
can penetrate the $\mathrm{OM}$ freely. In connection with the production of aminoglycosidemodifying enzymes, it has been demonstrated that where inactivation accompanies modification of the drug, the rate of loss of antibiotic potency is usually extremely low (Diedrichsen et al., 1977). Thus, although a certain amount of drug modification or inactivation or both, by the above enzymes, may occur, it is unlikely that this leads wholly to the expression of the resistance phenotype. It seems more likely that the impermeability of the OM, accompanied in some strains by the production of drug-inactivating enzymes as an additional resistance function, leads to the expression of resistance.

The data obtained, the fact that the LPS constitutes an exclusion barrier for carbenicillin and has a great affinity for gentamicin (Day, 1980), and the role of OM proteins in the function of the OM (Nakae and Nicaido, 1975; Nicas and Hancock, 1980; Osborn and Wu, 1980) should stimulate further interest in the molecular organisation of the OM and its role in the expression of the resistance phenotype. Work is in progress to study the OM proteins and to analyse the lipopolysaccharides of these strains.

\section{REFERENCES}

Ames G F-L, Spudich E N, Nikaido H 1974 Protein composition of the outer membrane of Salmonella typhimurium: Effect of lipopolysaccharide mutations. Journal of Bacteriology 117:406-416.

Barrett E, Asscher A W 1972 Action of ethylenediaminetetra-acetic acid (EDTA) on carbenicillin-resistant strains of Pseudomonas aeruginosa. Journal of Medical Microbiology 5:355-359.

Bauer A W, Kirby W M M, Sherris J C, Turck M 1966 Antibiotic susceptibility testing by a standardized single disk method. American Journal of Clinical Pathology 45:493-496.

Brokopp C D, Gomez-Lus R, Farmer J J 1977 Serological typing of Pseudomonas aeruginosa: Use of commercial antisera and live antigens. Journal of Clinical Microbiology 5:640-649.

Bryan L E, Van Den Elzen H M 1977 Spectrum of antibiotic resistance in clinical isolates of Pseudomonas aeruginosa. In: Schlessinger D (ed) Microbiology. American Society for Microbiology, Washington D.C., pp 164-168.

Chester I R, Meadow P M, Pitt T L 1973 The relationship between the O-antigenic lipopolysaccharides and serological specificity in strains of Pseudomonas aeruginosa of different O-serotypes. Journal of General Microbiology 78:305-318.

Davies J 1979 General mechanisms of antimicrobial resistance. Reviews of Infectious Diseases 1:23-29.

Day D F 1980 Gentamicin-lipopolysaccharide interactions in Pseudomonas aeruginosa. Current Microbiology 4:277-281.

Diedrichsen A, Bang J, Heding H 1977 A new type of inactivation of streptomycin by E. coli. Journal of Antibiotics 30:83-87.

Eagon R G 1974 Ultrastructure of the cell envelope of Pseudomonas aeruginosa: electron microscopic and chemical observations. Journal of Infectious Diseases 130 (suppl):65-80.

Elliot T S J, Greenwood D 1984 The morphological response of Pseudomonas aeruginosa to azthreonam, cefoperazone, ceftazidime and $\mathrm{N}$-formimidoyl thienamycin. Journal of Medical Microbiology 17:159-169.

Gilleland H E, Lyle R D 1979 Chemical alterations in cell envelopes of polymyxin-resistant Pseudomonas aeruginosa isolates. Journal of Bacteriology 138:839-845.

Gilleland H E, Murray R G E 1976 Ultrastructural study of polymyxin-resistant isolates of Pseudomonas aeruginosa. Journal of Bacteriology 125:267-281.

Hoekstra D, Van Der Laan J W, De Leij L, Witholt B 1976 Release of outer membrane fragments from normally growing Escherichia coli. Biochimica et Biophysica Acta 455:889-899. 
Holmes R K, Minshew B H, Gould K, Sanford J P 1974 Resistance of Pseudomonas aeruginosa to gentamicin and related aminoglycoside antibiotics. Antimicrobial Agents and Chemotherapy 6:253-262.

Irvin R T, Govan J W R, Fyfe J A M, Costerton J W 1981 Heterogeneity of antibiotic resistance in mucoid isolates of Pseudomonas aeruginosa obtained from cystic fibrosis patients: role of outer membrane proteins. Antimicrobial Agents and Chemotherapy 19:1056-1063.

Koike M, Iida K, Matsuo T 1969 Electron microscopic studies on the mode of action of polymyxin. Journal of Bacteriology 97:448-452.

Koplow J, Goldfine H 1974 Alterations in the outer membrane of the cell envelope of heptose-deficient mutants of Escherichia coli. Journal of Bacteriology 117:527-543.

Koval S F, Meadow P M 1977 The isolation and characterization of lipopolysaccharide-defective mutants of Pseudomonas aeruginosa PAC 1. Journal of General Microbiology 98:387-398.

Legakis N J, Papavassiliou J 1975 In vitro activity of ticarcillin, carbenicillin and ampicillin against some Gram-negative bacilli. Journal of Antibiotics 28:912-919.

Legakis N J, Tselentis J, Courtis K J, Papavassiliou J 1979 Cross-resistance of clinical isolates of Pseudomonas aeruginosa to five aminoglycosides. Journal of Antimicrobial Chemotherapy 5:487-490.

Legakis N J, Aliferopoulou M, Papavassiliou J, Papapetropoulou M 1982 Serotypes of Pseudomonas aeruginosa in clinical specimens in relation to antibiotic susceptibility. Journal of Clinical Microbiology 16:458-463.

Lianou P E, Bassaris H P, Daikos G K, Katsorchis T A, Legakis N J 1980 Increased adherence to human epithelial cells of resistant Pseudomonas aeruginosa strains. Journal of Infection 2:354-359.

Meadow P M 1975 Wall and membrane structure in the genus Pseudomonas. In: Clarke P H, Richmond M H (eds) Genetics and biochemistry of Pseudomonas. John Wiley, London, pp 67-98

Meadow PM, Wells P L, Salkinosa-Salonen M, Nurmiaho E-L 1978 The effect of lipopolysaccharide composition on the ultrastructure of Pseudomonas aeruginosa. Journal of General Microbiology 105:23-28.

Nakae T, Nikaido H 1975 Outer membrane as a diffusion barrier in Salmonella typhimurium: Penetration of oligo- and polysaccharides into isolated outer membrane vesicles and cells with degraded peptidoglycan layer. Journal of Biological Chemistry 250:7359-7365.

Nikaido H, Nakae T 1979 The outer membrane of Gram-negative bacteria. Advances in Microbial Physiology 20:163-250.

Nicas T I, Hancock R E W 1980 Outer membrane protein H1 of Pseudomonas aeruginosa: Involvement in adaptive and mutational resistance to ethylenediaminetetraacetate polymyxin B and gentamicin. Journal of Bacteriology 143:872-878.

Osborn M J, Wu H C P 1980 Proteins of the outer membrane of Gram-negative bacteria. Annual Review of Microbiology 34:369-422.

Penketh A, Pitt T, Roberts D, Hodson M E, Batten J C 1983 The relationship of phenotype changes in Pseudomonas aeruginosa to the clinical condition of patients with cystic fibrosis. American Review of Respiratory Disease 127:605-608.

Richmond M H 1978 Factors influencing the antibacterial action of $\beta$-lactam antibiotics. Journal of Antimicrobial Chemotherapy 4 (Suppl B):1-14.

Richmond M H, Curtis N A C 1974 The interplay of $\beta$-lactamases and intrinsic factors in the resistance of Gram-negative bacteria to penicillins and cephalosporins. Annals of the New York Academy of Sciences: 235:553-568.

Roantree R J, Kuo T T, MacPhee D G 1977 The effect of defined lipopolysacharide core defects upon antibiotic resistances of Salmonella typhimurium. Journal of General Microbiology 103:223-234.

Stinnett J D, Gilleland H E, Eagon RG 1973 Proteins released from cell envelopes of Pseudomonas aeruginosa on exposure to ethylenediamine tetraacetate: comparison with demethylformamide-extractable proteins. Journal of Bacteriology 114:399-407. 